\title{
Leucemia/linfoma T del adulto en pacientes infectados con HTLV-1: reporte de dos casos de Colombia
}

\author{
Edwin Abraham Medina, Rocío Orduz, Olga Lucía Morales, Óscar Martínez, \\ Margarita Baldión, Mario Arturo Isaza \\ Clínica Colsanitas, Bogotá, D.C., Colombia
}

\begin{abstract}
La leucemia/linfoma de células T del adulto (Adult T-Cell Leukemia/Lymphoma, ATLL) es una neoplasia maligna de los linfocitos T CD4 maduros, que resulta de la infección con el virus T-linfotrópico humano de tipo 1 (HTLV-1), con varias manifestaciones sistémicas y cutáneas. Se presentan dos casos de leucemia/linfoma de células T del adulto en pacientes del suroccidente de Colombia, cuyos diagnósticos fueron confirmados por histología, inmunohistoquímica, citometría de flujo y pruebas ELISA y Western blot. También, se discute acerca del virus y cómo hacer el diagnóstico en países como el nuestro.
\end{abstract}

Palabras clave: virus 1 linfotrópico T humano, leucemia-linfoma de células T del adulto; leucemia de células $\mathrm{T}$, linfoma de células $\mathrm{T}$.

doi: http://dx.doi.org/10.7705/biomedica.v33i4.1429

\begin{abstract}
Adult T-cell leukemia/lymphoma in HTLV-1 infected patients: report of two cases in Colombia
Adult T-cell leukemia/lymphoma (ATLL) is a malignant neoplasia of mature CD4+ T lymphocytes, resulting from infection with human T-lymphotropic virus type 1 (HTLV-1), with several systemic and cutaneous manifestations.

We present two cases of adult T-cell leukemia/lymphoma, in patients from the Colombian Southwestern region, whose diagnoses were confirmed by histology, immunohistochemistry, flow cytometry, ELISA and Western blot tests. We also discuss about the virus and how to make this diagnosis in countries like Colombia.
\end{abstract}

Keywords: Human T-lymphotropic virus 1; leukemia-lymphoma, adult T-cell; leukemia, T-cell; lymphoma, T-cell.

doi: http://dx.doi.org/10.7705/biomedica.v33i4.1429

Hace aproximadamente 35 años fue descrita en Japón por Uchiyama y otros, una neoplasia de células T denominada leucemia/linfoma de células $T$ del adulto o leucemia de células T del adulto (ATLL) (1). Más tarde, en 1980, se descubrió la asociación entre esta enfermedad y un virus clasificado como un "retrovirus de tipo C" el cual se denominaba virus T-linfotrópico humano de tipo 1 (HTLV-1) (2). Existen varias formas de transmisión: de madre a hijo, principalmente mediante la lactancia; por vía sexual y vía parenteral por transfusión

\section{Correspondencia:}

Olga Lucía Morales, Laboratorio Clínico, Clínica Colsanitas, Carrera 69C N99-45, Bogotá, D.C., Colombia

Teléfono: (571) 5895482

olmorales@colsanitas.com

Recibido: 04/10/12; aceptado:26/06/13 de componentes sanguíneos infectados o por compartir agujas y jeringas (3).

La leucemia/linfoma de células $T$ del adulto es una enfermedad maligna linfoproliferativa agresiva de células T periféricas, con una corta supervivencia en su forma aguda y una incidencia menor de $5 \%$ en personas infectadas con el HTLV-1 (4). Actualmente, esta enfermedad está bien reconocida por la Organización Mundial de la Salud y existe consenso diagnóstico sobre sus características morfológicas, inmunofenotipo y alteraciones genéticas (5). Se ha establecido la integración monoclonal del HTLV-1 y se han identificado dos proteínas involucradas en la progresión de la enfermedad (6).

En este reporte se presentan y discuten dos casos recientemente diagnosticados como leucemia/

\section{Contribución de los autores:}

Edwin Abraham Medina y Rocío Orduz: descripción clínica y análisis de los casos clínicos y aportes en la discusión.

Olga Lucía Morales: revisión metodológica y preparación del manuscrito.

Oscar Martínez: aportes en la introducción y discusión.

Margarita Baldión: aportes en la discusión.

Mario Arturo Isaza: asesoría metodológica y seguimiento. 
linfoma de células $\mathrm{T}$ del adulto en un servicio de patología de alta complejidad en Colombia.

\section{Caso 1}

Se trata de una mujer de 58 años de edad, proveniente de Orito, Putumayo (Amazonia colombiana), que consultó por diarrea recurrente, tratada en forma repetida con agentes antiparasitarios por hallazgos de estrongiloidiasis en materia fecal. La paciente fue referida al Hospital Universitario Clínica Universitaria Colombia, ubicado en Bogotá.

Presentaba dilatación del conducto biliar extrahepático demostrada por resonancia magnética (colangiorresonancia). Presentaba niveles de deshidrogenasa láctica de $337 \mathrm{mg} / \mathrm{dl}$ y no tenía reporte de calcio sérico (cuadro 1). En la revisión por sistemas, refería malestar e importante pérdida de peso; no se observaron manifestaciones cutáneas. Tenía una historia previa de proctitis crónica no específica, colecistectomía, histerectomía, obstrucción intestinal secundaria a adherencias pélvicas e infecciones frecuentes de vías urinarias.

Después de una biopsia no diagnóstica de la ampolla de Vater, la paciente requirió una pancreatoduodenectomía. En la mucosa duodenal se observó una neoplasia linfoide pleomorfa de células grandes, con expresión difusa de CD3, CD4 y CD56; CD20 y CD30 focal, un índice de proliferación (MIB1) de $60 \%$ y eosinofilia tisular asociada (figura 1), lo que llevó a un diagnóstico de linfoma $T$ periférico, NOS (Peripheral T-Cell Lymphoma, Not Otherwise Specified). Se determinó la ausencia de compromiso de la medula ósea por histología y citometría de flujo.

Considerando como diagnóstico diferencial la leucemia de células T del adulto, se ordenó una

Cuadro 1. Aplicación de criterios diagnósticos de leucemia/ linfoma de células T del adulto (ATLL) en los casos presentados

\begin{tabular}{lcc}
\hline Criterio & $\begin{array}{c}\text { Caso 1 } \\
\text { Tipo linfoma }\end{array}$ & $\begin{array}{c}\text { Caso 2 } \\
\text { Tipo leucemia } \\
\text { aguda }\end{array}$ \\
\hline $\begin{array}{l}\text { Linfocitosis } \\
\text { Linfocitos anormales }\end{array}$ & No & Sí \\
en sangre & No & Sí \\
LDH & Ligero incremento & $\begin{array}{c}\text { Ligero incremento } \\
\text { Calcio }\end{array}$ \\
$\begin{array}{l}\text { Anticuerpos anti-HTLV } \\
\text { 1/2 }\end{array}$ & Reactivo & Sin dato \\
Western blot HTLV 1/2 & Positivo para & Reactivo \\
& HTLV-1 & HTLV-1 \\
Exantema & No & No \\
Linfadenopatía & No & Sí \\
Hepatoesplenomegalia & No & Sí \\
Infiltración medular & No & Sí \\
\hline
\end{tabular}

prueba ELISA para HTLV1/2, la cual resultó positiva y se confirmó mediante una prueba de Western Blot, también positiva para HTLV-1 (presencia de bandas de discriminación p19-I, gp46-I y ausencia de GP46-II). El tipo de leucemia/linfoma de células T del adulto identificado correspondió a un linfoma agresivo. La paciente recibió cinco ciclos de quimioterapia combinada (CHOP) antes de su fallecimiento. No se hizo estudio post mórtem.

\section{Caso 2}

Se trata de una mujer de 71 años, proveniente de Palmira (población del suroccidente de Colombia cerca a la Costa Pacífica), referida a la Clínica Sebastián de Belalcázar de Cali, por historia de 20 días de evolución de fiebre y tos productiva, asociada a pérdida de peso de seis meses $(4 \mathrm{~kg})$ y una infección de vías aéreas superiores con tratamiento antibiótico y evolución tórpida.

En el examen físico se encontró hepatoesplenomegalia y adenopatía de $3 \mathrm{~cm}$ en la axila derecha; no se observaron manifestaciones cutáneas.

En el cuadro hemático inicialmente se observó anemia y leucopenia, seguidas por leucocitosis, linfocitosis $\left(11.000 / \mathrm{mm}^{3}\right)$ y neutropenia absoluta. Se encontraron niveles de deshigrogenasa láctica de $300 \mathrm{mg} / \mathrm{dl}$ y calcio sérico de 7,1 mg/dl.

Se obtuvieron biopsias de ganglio linfático y médula ósea con el fin de descartar un linfoma. Estos dos tejidos y la sangre estaban infiltrados por una neoplasia de células $T$ con importante pleomorfismo nuclear (figuras 2 y 3 ). En los extendidos de sangre se observaron "células flor" (flower cells) y se identificó un fenotipo CD3+, CD2+, CD4+, CD5+, CD7-, CD8-, CD56- y TdTen las células tumorales, tanto en la biopsia de ganglio linfático como en la de médula ósea y en la citometría de flujo de sangre periférica.

Teniendo en cuenta los hallazgos anteriores, se sospechó una leucemia/linfoma de célula $\mathrm{T}$ del adulto; por consiguiente, se solicitaron las pruebas ELISA y Western Blot para HTLV 1-2, las cuales resultaron positivas, confirmando el diagnóstico. El resultado del Western blot fue positivo para HTLV-1 con presencia de bandas p19, GD21 y rgp46-I. La forma de leucemia identificada correspondió a leucemia aguda. La paciente falleció antes de iniciar el tratamiento.

\section{Discusión}

La leucemia/linfoma de células $T$ del adulto fue descrita originalmente en 1977 en una serie de 

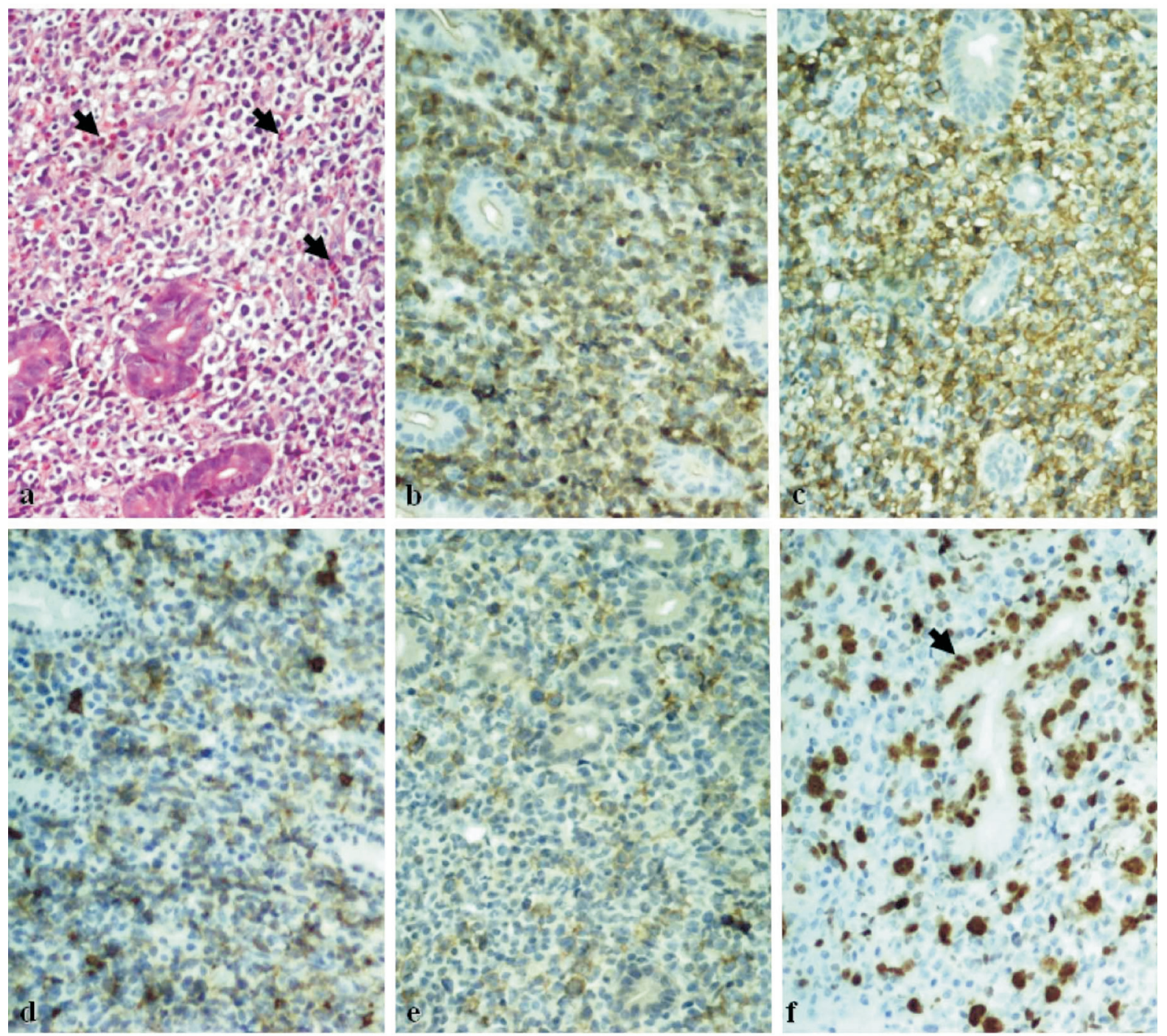

Figura 1. Pancreato-duodenectomía. No se identificó tumor macroscópico. La revisión microscópica del duodeno reveló una densa población linfoide atípica que se expandió a la lámina propia de la mucosa sin distorsión glandular (se muestran algunas glándulas atrapadas) y se observaron abundantes eosinófilos (flechas) (a, hematoxilina y esosina, 10X). Se realizaron tinciones de inmunohistoquímica que demostraron reacción fuerte y difusa con CD3 (b, 10X) y CD4 (c, 10X) en las células neoplásicas. Se evidenció co-expresión aberrante de CD20 débil (más fuerte en células B normales) (d, 10X) y CD30 débil (e, 10X). Se calculó un índice de proliferación (MIB1) cercano al $60 \%$; el índice de proliferación de una glándula reactiva atrapada fue de alrededor de 80 $\%$ (flecha) (f, $10 \mathrm{X})$.

casos de 16 pacientes nativos de una isla japonesa llamada Kyushu. La enfermedad fue definida como una leucemia de células $T$ maduras del adulto (1). Varios años después, algunas partículas de retrovirus de tipo $C$ fueron detectadas y aisladas de pacientes con linfomas cutáneos de células $T$ y se denominaron HTLV-1 (2). En 1982, el mismo virus se aisló en líneas celulares obtenidas de pacientes fallecidos por leucemia/linfoma de células $T$ del adulto en Japón (7). Por otra parte, en 1985 en Japón, se describieron asociaciones entre HTLV-1 y una enfermedad neurológica conocida como paraparesia espástica tropical (TSP) y mielopatía asociada a HTLV-1 (HAM) (8). Actualmente se sabe que estas dos enfermedades son mielopatías idénticas conocidas como HAM/TSP (9).

EI HTLV es un virus oncogénico con un genoma compuesto por una cadena sencilla de ARN que es capaz de infectar linfocitos $T$ y $B$, monocitos y células dendríticas y endoteliales. Sin embargo, la transformación maligna sólo se ha descrito en linfocitos $T$, originando la leucemia/linfoma de células T del adulto (10). A la fecha se han descrito cuatro tipos de HTLV (desde HTLV-1 hasta HTLV-4). Aunque 

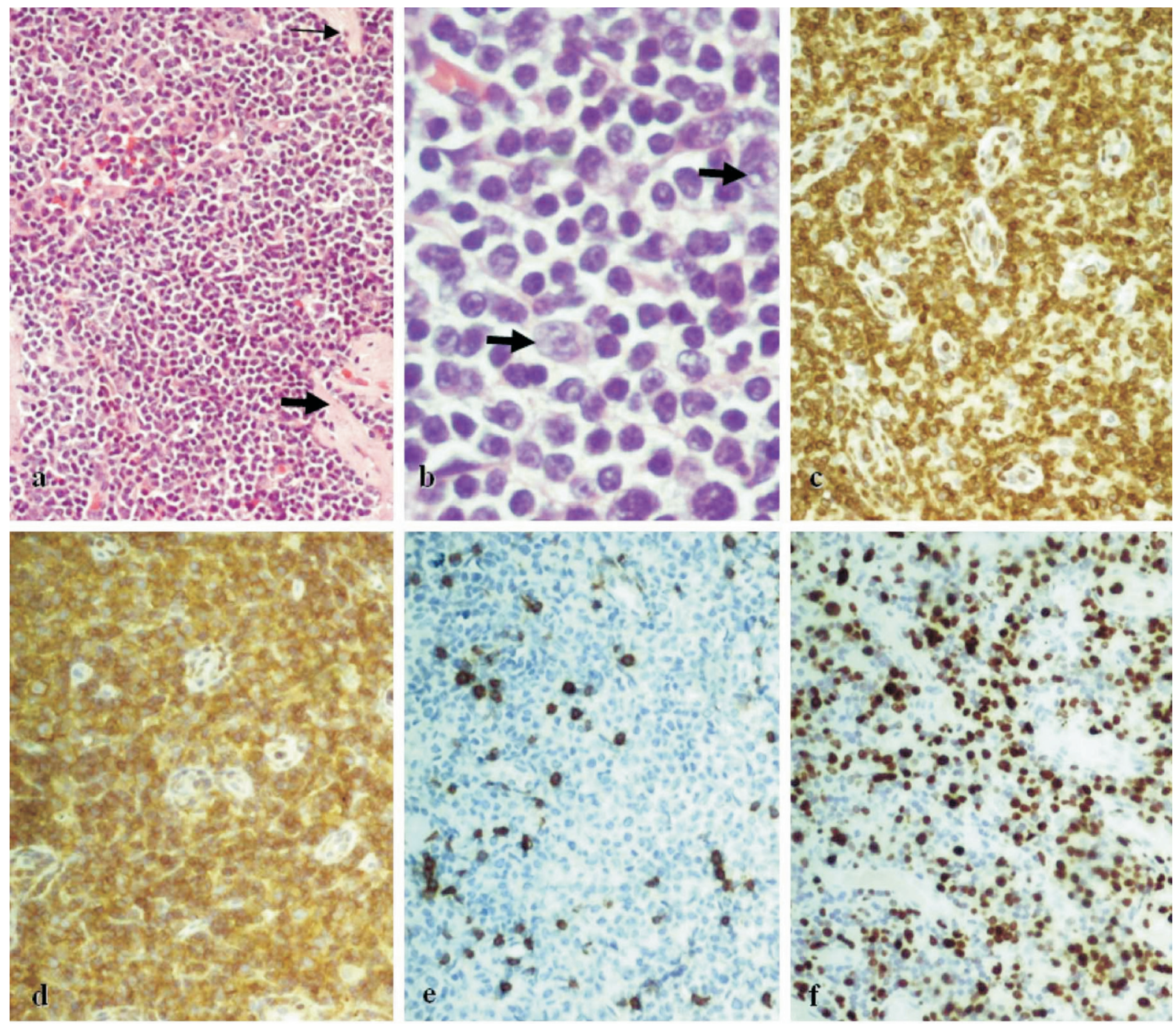

Figura 2. Biopsia del ganglio linfático. La arquitectura fue borrada por gruesas bandas de colágeno (flechas) y linfocitos medianos neoplásicos que infiltran difusamente la zona paracortical (a, hematoxilina y eosina, 10X). En un acercamiento de alto poder se evidenció la apariencia linfoide atípica y algunas células neoplásicas similares a blastos (flechas) (b, H\&E 40X). Se hicieron tinciones especiales de inmunohistoquímica, que revelaron expresión difusa de CD3 (c, 10X) y CD4 (d, 10 X) en células neoplásicas. No se observó expresión aberrante de CD7 en células neoplásicas (con reacción en algunas células T normales) (e, 10X). El índice de proliferación (MIB1) se estimó en alrededor de 70 \% (f, 10 X).

HTLV-2 no ha sido asociado con ATLL, este virus se ha encontrado en casos aislados de ciertas condiciones neurológicas Aunque el virus HTLV-2 no se ha asociado con este leucemia, se ha encontrado en casos aislados de ciertas condiciones neurológicas. Los otros dos tipos, HTLV-3 y HTLV-4, fueron descritos en el 2005 y no se han asociado con ninguna enfermedad en los seres humanos (11). Se ha determinado que el HTLV-1 induce la transformación leucémica de los linfocitos $T$ infectados mediante la activación de sus proteínas TAX y HBZ (cierre de leucina básico de HTLV-1, HTLV-1 basic-leucine zipper), las cuales en conjunto modulan actividades celulares tales como activación, supervivencia y mutación (12).
Las áreas del mundo con mayor prevalencia de infección por HTLV-1 son Japón, África, las islas caribeñas y Sur América (9). El virus se ha encontrado en todos los países latinoamericanos, con mayor prevalencia en Argentina, Brasil, Colombia y Perú. En Brasil se ha descrito una prevalencia de $0,41 \%$, con variaciones entre las diferentes áreas geográficas y socioeconómicas (13).

En Colombia la presencia de HTLV-1/2 se demostró en tejidos incluidos en bloques de parafina de pacientes con linfomas no Hodgkin en Cali, una ciudad de la región del Pacífico, usando una técnica de amplificación por PCR (cinco de 75 casos); en el mismo estudio se encontró serología 

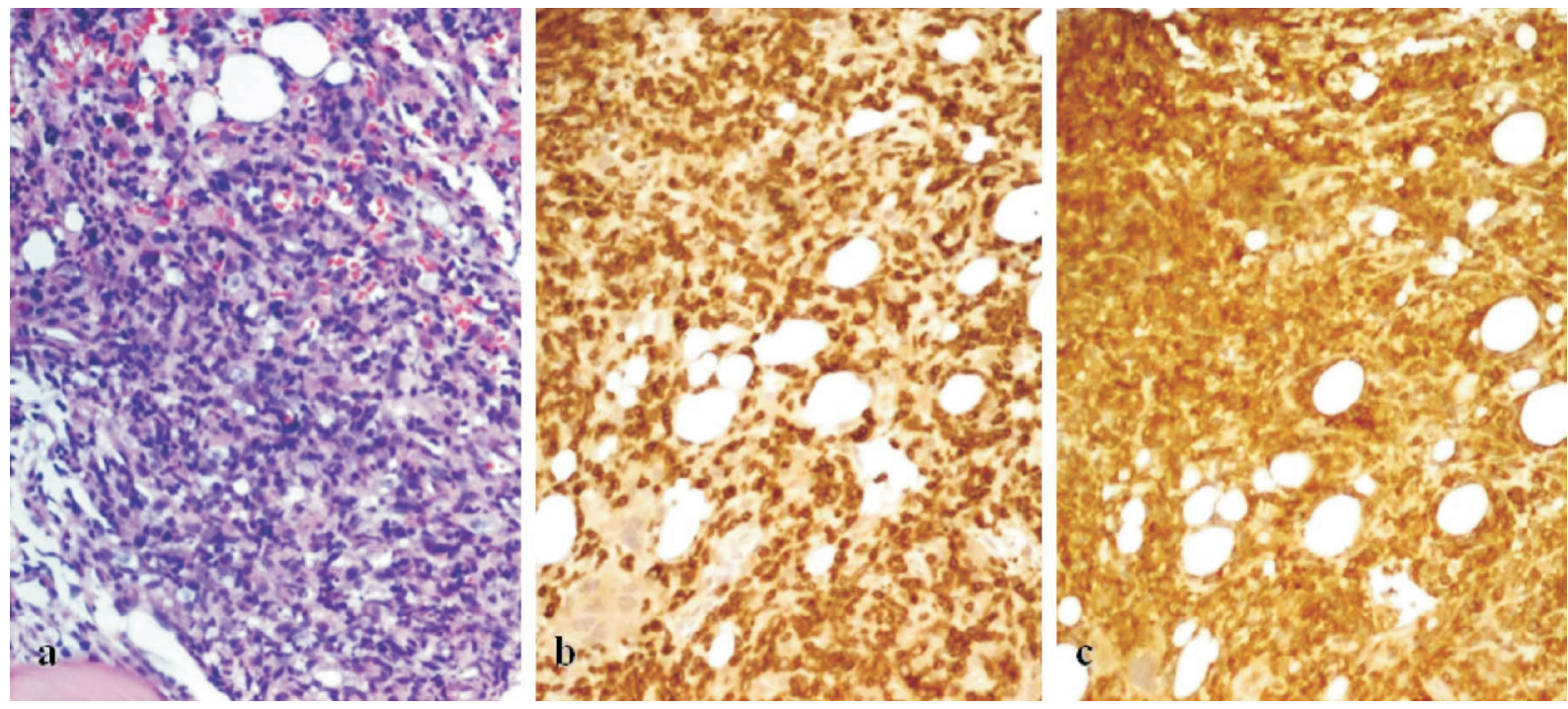

Figura 3. La médula ósea se ve comprometida por un tumor linfoide maligno que infiltra de forma difusa y sustituye la arquitectura normal (a, hematoxilina y eosina, 10X). Estas células neoplásicas son fuerte y difusamente reactivas para CD3 (b, 10X) y CD4 (c, 10X) por técnicas de inmunohistoquímica.

positiva en $5,1 \%$ de la población afro-colombiana de la localidad costera de Tumaco (14). En un estudio reciente en Bogotá, entre 8.913 donantes de sangre, se encontró una seroprevalencia de $0,07 \%(15)$.

Hay cuatro formas bien definidas de leucemia/ linfoma de células $\mathrm{T}$ del adulto: 1) leucemia aguda agresiva con presencia de células $T$ circulantes, maduras y pleomórficas, caracterizada además por hipercalcemia, visceromegalia y lesiones cutáneas (caso 2); 2) linfoma agresivo sin características de leucemia (caso 1); 3) enfermedad crónica, caracterizada por lesiones cutáneas y linfocitosis de células $T$, la cual con frecuencia puede permanecer estable por meses o años, y 4) asintomática o de lenta evolución, con algunas manifestaciones pulmonares o cutáneas (4). En general, estas neoplasias se desarrollan en aproximadamente el $5 \%$ de todos los individuos infectados, con una latencia de cerca de 30 años desde la primoinfección viral. Esta enfermedad se ha descrito predominantemente en adultos mayores, con un promedio de 58 años, lo cual se relaciona con el mencionado largo periodo de latencia de la infección viral (4).

Los dos casos que se presentan fueron tratados para infecciones recurrentes, lo cual demuestra la falla del sistema inmunitario (inmunidad celular). El primer caso presentó una infección tropical típica (estrongiloidiasis), lo cual se reconoce como un síntoma común de presentación en pacientes afectados por leucemia/linfoma de células $\mathrm{T}$ del adulto. La eosinofilia reportada en este primer caso es también un hallazgo común en personas con esta neoplasia (5). En contraste con muchos de los casos reportados, no se encontraron manifestaciones cutáneas en ninguno de los dos pacientes.

La leucemia/linfoma de células $\mathrm{T}$ del adulto se considera una enfermedad sistémica y durante la fase aguda presenta expansión extraganglionar que compromete el bazo, el hígado y la médula ósea (16). El caso 2 mostró estas características, presentándose con aumento de tamaño de los ganglios linfáticos y compromiso de medula ósea y sangre con las células características. Este caso también tuvo el peor pronóstico puesto que falleció durante el tratamiento inicial. En el caso 1, a pesar de la aparente cantidad mínima de enfermedad (confinada a la mucosa duodenal) sin compromiso de sangre, médula ósea ni ganglios linfáticos y con inicio temprano de quimioterapia, la paciente falleció cuatro meses después del diagnóstico.

Se observó infiltración difusa por células linfoides atípicas de tamaño mediano en la mucosa duodenal (caso 1), y en ganglios linfáticos y medula ósea (caso 2). Se observaron núcleos hipercromáticos, pleomorfismo nuclear y transformación blástica de las células tumorales, asociada con incremento del número de eosinófilos. Las típicas "células flor" se observaron en los frotis de sangre durante la transformación leucémica (caso 2, no se presenta 
la imagen). El inmunofenotipo registrado en este tipo de tumores (CD3+, CD4+, CD5+, CD7-, y CD8-) se observó en ambos casos (5). Otro antígeno reportado como CD30+, se observó también (caso 1). La expresión de CD20 en las células neoplásicas T, como se observó en el caso 1 , ha sido reportada en casos poco comunes y se constituye en una dificultad diagnóstica (17). En estos casos, se utilizó un marcador adicional, el PAX5, que es un marcador específico de linaje de células $B$, el cual resultó negativo (no se presenta la imagen). No se hicieron pruebas de integración monoclonal del HTLV-1 en ninguno de los casos.

Un par de casos de leucemia/linfoma de células $T$ del adulto se han reportado en Colombia, aunque la frecuencia de la infección por HTLV-1 en algunas áreas geográficas no es despreciable. Cuando existan características sugestivas de leucemia/ linfoma de células $T$ del adulto, es recomendable llevar a cabo al menos la prueba ELISA para detectar anticuerpos específicos contra HTLV 1/2 y, si esta prueba resulta reactiva, es necesario confirmar el resultado con una prueba más específica para HTLV-1, como el Western blot o la reacción en cadena de la polimerasa (PCR). Recomendamos enfáticamente practicar una prueba para HTLV$1 / 2$ en pacientes con diagnóstico de leucemia/ linfoma de células $T$ maduras, porque es claro que este virus linfotrópico puede ser responsable de la misma, más aun si el paciente procede de una zona endémica para HTLV.

El diagnóstico definitivo de leucemia/linfoma de células T del adulto requiere la demostración de la integración monoclonal de HTLV-1 (5); sin embargo, la prueba confirmatoria de clonalidad viral no está disponible en el país y es difícil practicarla en tejido incluido en bloques de parafina; esta prueba en sangre solo se hace con fines de investigación (6). En otros laboratorios de referencia, el diagnóstico hematopatológico de Estados Unidos y Europa, la prueba de clonalidad viral no se practica de forma rutinaria y a pesar de esto se hacen diagnósticos de leucemia/linfoma de células $T$ del adulto, basados usualmente en las características morfológicas y fenotípicas de la enfermedad, y en la presencia de anticuerpos para HTLV-1/2 mediante la técnica ELISA.

A pesar del aspecto morfológico característico en ambos pacientes y teniendo en cuenta que los dos casos procedían de zonas geográficas con conocida circulación del virus, el diagnóstico de leucemia/linfoma de células $T$ del adulto no se sospechó clínicamente. Lo anterior nos permite inferir que la prevalencia real de esta enfermedad en nuestro país esta subestimada, sumado a la muerte temprana de estos pacientes sin estudios de histopatología. Se sabe que la epidemiología del HTLV-1 se caracteriza por un agrupamiento geográfico; la infección es endémica en la Costa del Pacífico en Colombia, en el sur de Japón, en África y algunas áreas del Caribe (18).

El conocimiento preciso de la naturaleza y etiología de este tipo de neoplasias tiene implicaciones tanto para el pronóstico como para el tipo de tratamiento que se debe suministrar al paciente; de igual forma, es importante hallar la prevalencia de la infección con el fin de diseñar estrategias que favorezcan la prevención de la transmisión viral en la población, incluyendo medidas como impedir la lactancia materna en mujeres infectadas con el HTLV-1, hacer pruebas de tamización a todos los donantes de sangre, al igual que en donantes de órganos para trasplantes, entre otras. Con este propósito, también, se debería incluir la prueba de tamización para HTLV-1 entre las pruebas de control prenatal en áreas endémicas.

Aunque en nuestro medio existen limitaciones diagnósticas al carecer de pruebas específicas, la sospecha termina siendo la principal herramienta del personal clínico que se enfrenta a casos como los descritos en este reporte; entonces, es esencial conocer la epidemiología de la infección porque puede ser el eslabón determinante para el diagnóstico.

\section{Conflictos de interés}

Los autores declaran que no tienen potenciales conflictos de interés.

\section{Financiación}

Se hizo con recursos propios.

\section{Referencias}

1. Uchiyama T, Yodoi J, Sagawa K, Takatsuki K, Uchino H. Adult T-cell leukemia: Clinical and hematologic features of 16 cases. Blood. 1977;50:481-92.

2. Poiesz BJ, Ruscetti FW, Gazdar AF, Bunn PA, Minna JD, Gallo RC. Detection and isolation of type $C$ retrovirus particles from fresh and cultured lymphocytes of a patient with cutaneous T-cell lymphoma. Proc Natl Acad Sci USA. 1980;77:7415-9.

3. Manns A, Hisada M, La Grenade L. Human T-lymphotropic virus type I infection. Lancet. 1999;353:1951-8. http://dx.doi. org/10.1016/S0140-6736(98)09460-4,

4. Shimoyama M. A Report from Lymphoma Study Group (1984-87). Diagnostic criteria and classification of clinical 
subtypes of adult Tcell leukaemia lymphoma. $\mathrm{Br} \mathrm{J}$ Haematol. 1991;79:428-37.http://dx.doi.org/10.1111/j.1365-2141.1991. tb08051.x

5. Ohshima K, Jaffe ES, Kikuchi M. Adult T-cell leukaemia/ lymphoma. In: Swerdlow SH, Campo E, Harris NL, Jaffe ES, Pileri SA, Stein $\mathrm{H}$, et al., editors. WHO classification of tumours of haematopoietic and lymphoid tissues. Geneva: WHO Press; 2008. p. 281-4.

6. Okayama A, Stuver S, Matsuoka M, Ishizaki J, Tanaka G, Kubiki Y, et al. Role of HTLV-1 proviral DNA load and clonality in the development of adult T-cell leukemia/lymphoma in asymptomatic carriers. Int J Cancer. 2004;110:621-5. http:// dx.doi.org/10.1002/ijc.20144

7. Yoshida M, Miyoshi I, Hinuma Y. Isolation and characterization of retrovirus from cell lines of human adult T-cell leukemia and its implication in the disease. Proc Natl Acad Sci USA. 1982;79:2031-5.

8. Gessain A, Barin F, Vernant JC, Gout O, Maurs L, Calender A, et al. Antibodies to human T-lymphotropic virus type-I in patients with tropical spastic paraparesis. Lancet. 1885;8452:407-10.http://dx.doi.org/10.1016/S0140-6736 (85) $92734-5$

9. Proietti FA, Carneiro-Proietti AB, Catalan-Soares BC, Murphy EL. Global epidemiology of HTLV-I infection and associated diseases. Oncogene 2005;24:6058-68. http:// dx.doi.org/10.1038/sj.onc.1208968

10. Kannian P, Green PL. Human T Iymphotropic virus type 1 (HTLV-1): Molecular biology and oncogenesis. Viruses. 2010;2:2037-77. http://dx.doi.org/10.3390/v2092037

11. Proietti FA, Carneiro-Proietti AB. HTLV in the Americas. Rev Panam Salud Pública. 2006;19:7-8. http://dx.doi. org/10.1590/S1020-49892006000100002
12. Usui T, Yanagihara K, Tsukasaki K, Murata K, Hasegawa $\mathbf{H}$, Yamada $\mathbf{Y}$, et al. Characteristic expression of HTLV-1 basic zipper factor (HBZ) transcripts in HTLV-1 proviruspositive cells. Retrovirology. 2008;5:34. http://dx.doi.org/10. 1186/1742-4690-5-34

13. Galvão-Castro B, Loures L, Rodriques LG, Sereno A, Ferreira Júnior OC, Franco LG, et al. Distribution of human T-lymphotropic virus type I among blood donors: A nationwide Brazilian study. Transfusion. 1997;37:242-3. http://dx.doi.org/10.1046/j.1537-2995.1997.37297203532.x

14. Carrascal E, Cortés A, Akiba S, Tamayo O, Quiñónez F, et al. Epidemiología y patología de la leucemia/linfoma de las células T del adulto en Cali y el suroccidente colombiano. Colombia Médica. 2004;35:12-7.

15. MartínezO, Isaza M, RangeIN, Morales OL.Seroprevalencia de anticuerpos para virus linfotrópicos humanos (HTLV I/II) en donantes de sangre de una Clínica de Bogotá, Colombia. 1999-2004. Rev Salud Pública. 2007;9:253-61. http://dx.doi. org/10.1590/S0124-00642007000200009

16. Yasunaga J, Matsuoka M. Human T-cell leukemia virus type I induces adult T-cell leukemia: From clinical aspects to molecular mechanisms. Cancer Control. 2007;14:133-40.

17. Buckner CL, Christiansen LR, Bourgeois D, Lazarchick JJ, Lazarchick J. Case reports: CD20 positive T-cell lymphoma/leukemia: A rare entity with potential diagnostic pitfalls. Ann Clin Lab Sci. 2007;37:263-7.

18. Cortés A, García M. Prevalencia de marcadores para infecciones transmisibles por transfusión en donantes voluntarios. Colombia Médica. 1996;27:3-10. 